\title{
A randomized trial on the effects of root resorption after orthodontic treatment using pulsating force
}

\author{
Jue Wang ${ }^{1}$, Ejvis Lamani ${ }^{1}$, Terpsithea Christou' ${ }^{1}$, Peng Li ${ }^{2}$ and Chung How Kau ${ }^{1 *}$ (D)
}

\begin{abstract}
Background: An orthodontic device that moves teeth with pulsating force was invented and underwent a single center, controlled, clinical trial to test its safety and efficacy for treatment. The device has a custom-made thermoplastic mouthpiece which fits over the teeth with an inflatable silicone element. A console that measures and controls the pulsating force level in real-time controls the air pressure that delivers a pulsating force. In this study, the effect of the device on root resorption during orthodontic treatment was evaluated using 3D cone beam computed tomography and compared with a control group of patients who received Invisalign treatment.
\end{abstract}

Methods: Twenty-eight subjects were enrolled in the investigational arm and 15 in the control group. Subjects were followed until the average score of the mandibular and maxillary teeth achieved a Little's Irregularity Index of $1.5 \mathrm{~mm}$ or less.

Results: There were no adverse events reported throughout the study for either treatment arm. No clinically significant root resorption was observed for either group. The investigational device did not cause root resorption greater than the control group. Both devices produced a safety profile compared to current orthodontic techniques.

Conclusion: The investigational device did not produce more root resorption than similar conventional orthodontic appliances.

Trial registration: ClinicalTrials.gov, NCT03421886. Registered 12 January 2018 - Retrospectively registered.

Keywords: Radiographic evaluation, Root-crown ratios, Clear aligners, Tooth movement, Cone beam computed tomography

\section{Background}

Efforts have been continuously made in the orthodontic field to provide a more effective, esthetic, and comfortable ways of treatment for orthodontic patients. Optimum orthodontic force is critical for the effectiveness and efficiency of orthodontic treatment. However, monitoring the magnitude of the orthodontic force

\footnotetext{
* Correspondence: ckau@uab.edu

${ }^{1}$ Department of Orthodontics, School of Dentistry, Univeristy of Alabama at Birmingham, Room 305, School of Dentistry Building, 1919 7th Avenue South, Birmingham, AL 35294, USA

Full list of author information is available at the end of the article
}

applied by current orthodontic appliances is difficult. Uncontrolled orthodontic force can collapse blood vessels within the periodontal ligament (PDL) leading to undesirable side effects. The cycle of PDL damage (hyalinized area formation and later undermining bone resorption) and repair is usually the main reason for prolonged orthodontic treatment and root damage.

Both in vitro and in vivo studies have shown that fully controlled pulsating orthodontic force can shorten the treatment period by potentially preventing the damage to capillary vessels within the PDL [1-4]. The effect of intermittent force versus continuous force on the

(c) The Author(s). 2020 Open Access This article is licensed under a Creative Commons Attribution 4.0 International License, which permits use, sharing, adaptation, distribution and reproduction in any medium or format, as long as you give appropriate credit to the original author(s) and the source, provide a link to the Creative Commons licence, and indicate if changes were made. The images or other third party material in this article are included in the article's Creative Commons licence, unless indicated otherwise in a credit line to the material. If material is not included in the article's Creative Commons licence and your intended use is not permitted by statutory regulation or exceeds the permitted use, you will need to obtain permission directly from the copyright holder. To view a copy of this licence, visit http://creativecommons.org/licenses/by/4.0/ The Creative Commons Public Domain Dedication waiver (http://creativecommons.org/publicdomain/zero/1.0/) applies to the data made available in this article, unless otherwise stated in a credit line to the data. 
amount of molar movement was examined in rats [3]. The results showed that $70 \%$ of the tooth movement was achieved within $8 \mathrm{~h}$ of intermitted force (33.3\% relative to continuous). In addition, previous study using rats showed that an activation of force for $12 \mathrm{~h}$ with 12$h$ rest produced similar tooth movement results to those achieved when force was applied the whole day [4]. It is also indicated that there is a diurnal variation regarding the tooth's response to orthodontic force, and that the force applied during the animal's rest period may be more effective than that applied during its active period. Notably, when pulsating force was applied to human maxillary molars, it is found that both the rate of movement and the total movement of the treated tooth was greater than that of the controlled tooth [1].

Safety is always the first concern when introducing an innovation into the medical field. Root resorption has been known as an unavoidable side effect of orthodontic treatment and has degrees of variability. It has been shown that the resorption in the majority of teeth is less than 2.5 $\mathrm{mm}$ and differs in the range of $10 \%$ for different teeth [58]. In addition, the Malmgren index has classified severe root resorption as more than $4 \mathrm{~mm}$ and $1-5 \%$ of the root length [9]. The severity of root resorption during orthodontic treatment varies largely, and is closely related to multiple factors. Genetics, ethnicity, individual biological variables, and mechanical factors are common factors found relevant [10-13]. Moreover, root morphology, tooth abnormalities, trauma, and severity of malocclusion also play a part [14]. Notably, mechanical factors, such as type of appliances used, and magnitude and direction of the force applied, are associated with the severity of root resorption during orthodontic treatment [15-17]. Thus, evaluating tooth root resorption is a critical part of assessing the safety profile of an orthodontic appliance.

Due to its advantages of comfort and esthetics, clear aligners have become increasingly popular among patients seeking orthodontic treatment $[18,19]$. It also presents as a safe orthodontic appliance as it is found that the prevalence and severity of external root resorption in patients with clear aligners were less than those in patients with fixed appliances [20, 21]. Thus, we designed the study to assess the external root resorption in patients treated with the innovative device which delivers pulsating orthodontic force through inflatable silicone element and compared it with that in patients treated with clear aligner. Threedimensional cone beam computed tomography (CBCT) was used in the present study as a reliable way to measure tooth crown and root length [22, 23].

\section{Methods}

\section{Study design}

The study was approved by the University of Alabama at Birmingham Institutional Review Board (IRB Protocol
Number F160418007). The study was designed as an open label, two-arm study with concurrent, randomized treatment and control groups. The study was conducted at a single site, the Department of Orthodontics, University of Alabama at Birmingham.

Subjects were derived from incoming patients seeking orthodontic treatment using clear aligners. When such a patient arrived, they were offered the opportunity to be enrolled in the trial. The protocol specified a sample size of 45 subjects with allocation ratio of 2:1 between the treatments (30 active and 15 control). The investigational group received the orthodontic device that delivers pulsating force (Aerodentis System, Dror Orthodesign, Jerusalem, Isreal) while the control group received clear aligners (Invisalign, Align Technology, California, USA). Subjects were followed for a total of up to 15 months or until achieving a Little's index of $<1.5$, whichever came first.Subjects will be assigned to one of the treatment arms according to randomization list, which was generated using a computerized algorithm. Randomization codes were sealed in individual envelopes per patient. The envelopes were opened only when a single randomization occurred, in order to avoid bias.

\section{Patient recruitment}

Prior to enrolling subjects in the study, the investigator orthodontist determined through screening if the subject qualifies for the study and if the investigational device is an appropriate treatment option for the subject using the following enrollment criteria: 1) permanent dentition; 2) class 1 malocclusion with crowding of $<6 \mathrm{~mm}$ or Mild class II, class II subdivision; 3) good oral hygiene. The exclusion criteria for the study were as follows: 1 ) any medical or dental condition that could negatively affect study results during the expected length of the study; 2) subject is currently using any investigational drug or any other investigational device; 3 ) subject plans to relocate or move during the treatment period; 4) allergic to acetaminophen (use of aspirin or non-steroidal anti-inflammatory drugs is excluded for subjects while on the study); 5) use of bisphosphonates (osteoporosis drugs) during the study; 6) pregnant females; 7) subjects that are likely unwilling to be compliant with device use, as determined by the questionnaire for compliance. All subjects enrolled in the study met all the enrollment criteria.

\section{Investigational device}

The investigational device [24] was recently approved by Food and Drug Administration of United States (FDA \#: K192069). It consists of two main components (Fig. 1):

1. A thermo-plastic mouthpiece with an integrated inflatable silicone element. The mouthpiece is 


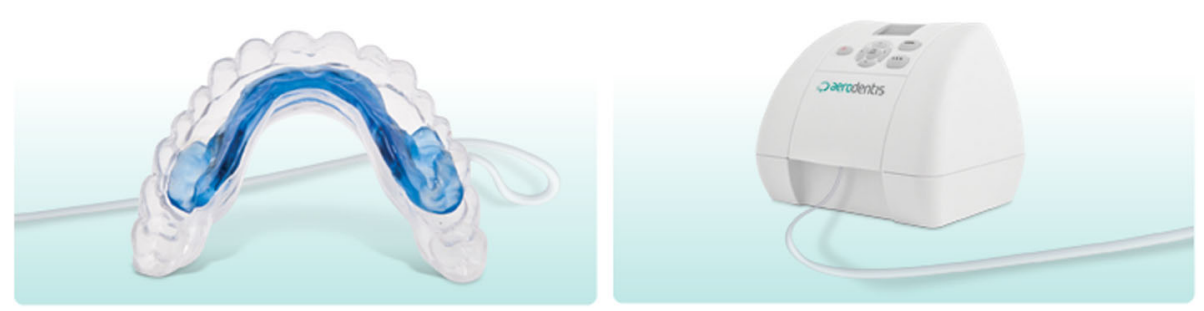

Fig. $1 \mathrm{~A}$ thermo-plastic mouthpiece with an integrated inflatable silicone element and the console

specifically designed for the subject and produced from orthodontic sheets by vacuum forming technology using CAD/CAM (computer-assisted design/computer assisted manufacturing) and 3D imaging.

2. A small easy-to-operate console with a user-friendly interface. It houses the electronics, air pump system and pressure sensor that measures and controls the electronic pulsating force level in real-time. An easy to use smart card monitors subject's compliance in treatment.

The inflatable element replaces the wires and brackets of traditional metal braces. Movement is achieved by applying pneumatic force on the buccal or and lingual surfaces of the teeth being treated.

\section{Measuring root resorption by $\mathrm{CBCT}$}

Previous studies have shown that the CBCTs are good sources to measure root resorption [25, 26]. All CBCT images were taken using the Kodak 9300 CBCT (Carestream Dental LLC, USA) machine. The CBCT scan of a patient was taken with a voxel resolution of $0.3 \mathrm{~mm}$. Each scan was saved in a Dicom file format. Two CBCT scans were taken (one at each time point) before orthodontic treatment (T1) and at the completion of tooth alignment (T2). As the pulsating force of the investigational device only applies to the maxillary and mandibular anterior teeth, measurements were performed on 12 teeth (maxillary and mandibular canines and incisors). All CBCT scans were approved by IRB and consented by the participants.

Crown and root lengths were measured and analyzed by using a method developed by Lind [27] and modified by Holtta et al. [28]. Midpoint was visually determined along a line bisecting the buccal and lingual cementoenamel junctions (CEJ) (Fig. 2). All the teeth measured were single-rooted teeth as only anterior teeth were included. Thus, each root was measured from the apex to the corresponding midpoint. All crown heights were measured from the CEJ midpoints perpendicular to the incisal/occlusal reference line (formed tangent to incisal edge or buccal cusps). Root resorption for an individual tooth was assessed using the following formula:

$$
\begin{aligned}
& E A R R=\text { Root }_{0} \frac{\text { Crown }_{f}}{\text { Crown }_{0}}-\text { Root }_{f} \\
& E A R R \text { Ratio }=\frac{\text { EARR }}{\text { Root }_{0}}
\end{aligned}
$$

Where EARR is external apical root resorption, $\mathrm{f}$ is the final measurement, and 0 is the baseline measurement.

\section{Teeth movement assessment (LII)}

Teeth movement was assessed by measuring Little's Index at 7 weeks and every 2 months thereafter. Tooth misalignment was measured in millimeters by means of a caliper and Little's Index was calculated.

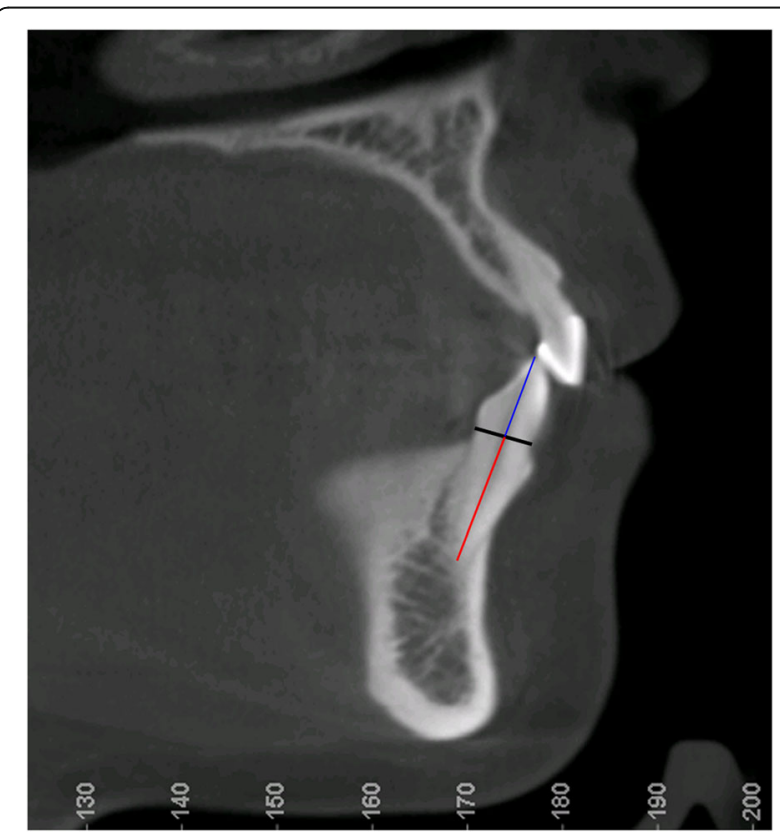

Fig. 2 Measurement of tooth crown length (blue line) and root length (red line) on CBCT 


\section{Statistics}

The sample size was calculated based on previous root resorption studies with similar study designs $[20,29,30]$. When the sample sizes in the groups are 15 and 30, a two-group large-sample normal approximation test of proportions with a one-sided 0.05 significance level will have $80 \%$ power to reject the null hypothesis that the test and the standard are not equivalent.

The patients' demographic and clinical characteristics were summarized as mean and standard deviation (SD) for continuous variables or frequency and proportion for categorical variables. EARR and EARR ratio were summarized at both tooth and patient level. The group comparison of EARR or EARR ratio at tooth level was conducted using Wilcoxon test while patient level comparison was conducted with a random effect model to take the clustering effect (multiple teeth within one patient) into account. The false discovery rate (FDR) was used for the multiple comparison correction. The correlation between LII and patient level EARR or EARR ratio was evaluated using Spearman correlation coefficient. $P<0.05$ or $\mathrm{FDR}<0.05$ given multiple comparison was considered as statistically significant. All the analysis was conducted using SAS 9.4 (Cary, NC).

\section{Results}

\section{Subjects}

A total of 36 investigational and 15 control subjects were enrolled into the trial from August 2016 through June 2018. However, 8 of the investigational subjects were excluded after consent as they chose not to participate further or did not conform to the compliance regime. Of the remaining 28 investigational and 15 control subjects, 5 investigational subjects and 2 control subjects did not complete the trial. For the investigational subjects, failure to complete the treatment were due to balloon leakage issues, technical issues with the console, and mouthpiece retention issue. The subjects withdrew from the control group stated that they preferred fixed appliances. All subjects that remained in the trial successfully achieved the primary endpoint. No subjects withdrew as a result of adverse events.

Demographics of the participants were shown in Table 1 . Subject age ranged from 12 to 65 , with the

Table 1 Baseline characteristics of participants in the two groups

\begin{tabular}{lll}
\hline & Aerodentis $(N=28)$ & Control $(N=15)$ \\
\hline $\begin{array}{l}\text { Age (Years) (Mean } \pm S D) \\
\text { Sex }(N, \%)\end{array}$ & $30.6 \pm 12.0$ & $32.3 \pm 16.4$ \\
$\quad$ Male & $4(14.3 \%)$ & $5(33.3 \%)$ \\
Female & $24(85.7 \%)$ & $10(66.7 \%)$ \\
\hline
\end{tabular}

average age being 31 . The majority of subjects were female (86\%), consistent with most aesthetic devices.

\section{Root morphology measurements at T2 compared to T1}

The safety endpoint was the incidence of adverse events, whether or not treatment related, and the amount of root resorption, as measured by comparing $\mathrm{x}$-rays before and at the end of tooth alignment. There were no adverse events reported for either the investigational or control devices.

The EARR for the investigation subjects (averaged across all teeth) was $0.16 \pm 0.172 \mathrm{~mm}$ and $0.071 \pm 0.045$ $\mathrm{mm}$ for control subjects with resorption ranging from 0 to $0.84 \mathrm{~mm}$ for the investigational group and $0.0-0.2$ $\mathrm{mm}$ for the control group (Table 2). After multiple testing correction, no significant difference was observed for all teeth. The analysis for EARR Ratio yielded similar results, with the root resorption ratio (averaged across all teeth) $1.238 \%( \pm 1.326 \%)$ in the investigational group and $0.511 \%( \pm 0.359 \%)$ in the control group (Table 3$)$. In any event, the extent of root resorption is minor and not expected to be clinically relevant as it is in the range of normal root resorption $[26,31]$ and less than $1 \mathrm{~mm}$, which is the generally accepted limit.

\section{Correlation between LII and root resorption}

LII was calculated for both maxilla and mandible for all the patients; for the experiment group, this ranged from $0.5-14.45 \mathrm{~mm}$ and, for the control group, $0.7-13.5 \mathrm{~mm}$, which illustrates the degree of crowding. Positive correlation was found between LII and the severity of root resorption but not statistically significant, possibly due to small sample size (Table 4).

\section{Discussion}

No adverse events were reported throughout the study for either study arm, suggesting that the device was safe for clinical purpose. Although the mean EARR for the investigation subjects was larger than that for the control group, the difference was not statistically significant. As a result, the investigational device has a comparable safety profile to the predicate from the perspective of root resorption.

Both panoramic radiographs and CBCT were used in the earlier studies to assess tooth root length [20, 21, 26, 30]. Currently, CBCT has been widely used in orthodontic treatment as an important tool for determining impacted tooth location [32], facial asymmetry [33], supernumerary teeth, temporomandibular joint (TMJ) pathology [34], airway construction, as well as for surgical planning $[35,36]$. Previous study has shown that the tooth length and root length measured by CBCT has no significant difference from the actual tooth length, 
Table 2 Root resorption measurement: EARR change from baseline in the two groups

\begin{tabular}{|c|c|c|c|c|}
\hline EARR $($ mean $\pm S D, m m)$ & Aerodentis & Control & P-value & $F D R$ \\
\hline Maxillary right canine & $0.21 \pm 0.22$ & $0.06 \pm 0.04$ & 0.0177 & 0.1011 \\
\hline Maxillary right lateral incisor & $0.12 \pm 0.11$ & $0.08 \pm 0.03$ & 0.203 & 0.2436 \\
\hline Maxillary right central incisor & $0.12 \pm 0.10$ & $0.09 \pm 0.04$ & 0.3094 & 0.3094 \\
\hline Maxillary left central incisor & $0.11 \pm 0.16$ & $0.04 \pm 0.02$ & 0.1129 & 0.1694 \\
\hline Maxillary left lateral incisor & $0.20 \pm 0.17$ & $0.09 \pm 0.05$ & 0.0292 & 0.1011 \\
\hline Maxillary left canine & $0.13 \pm 0.13$ & $0.09 \pm 0.06$ & 0.2614 & 0.2852 \\
\hline Mandibular right canine & $0.21 \pm 0.22$ & $0.09 \pm 0.06$ & 0.0513 & 0.1025 \\
\hline Mandibular right lateral incisor & $0.14 \pm 0.16$ & $0.07 \pm 0.04$ & 0.1303 & 0.1737 \\
\hline Mandibular right central incisor & $0.17 \pm 0.19$ & $0.06 \pm 0.05$ & 0.0561 & 0.1025 \\
\hline Mandibular left central incisor & $0.13 \pm 0.09$ & $0.07+0.04$ & 0.0317 & 0.1011 \\
\hline Mandibular left lateral incisor & $0.15 \pm 0.16$ & $0.06 \pm 0.03$ & 0.0598 & 0.1025 \\
\hline Mandibular left canine & $0.23 \pm 0.26$ & $0.07 \pm 0.06$ & 0.0337 & 0.1011 \\
\hline
\end{tabular}

SD Standard deviations, FDR False discovery rate

indicating that $\mathrm{CBCT}$ scan provides enough accuracy for tooth crown and root length measurement [22].

Tooth root resorption related to orthodontic treatment mainly occurs in the anterior teeth [37, 38]. Since the inflatable silicone element in the mouthpiece of the investigational device extends only in the anterior region, root measurements were made to the area of anatomy. Previous studies on tooth root resorption also focused on the anterior teeth for practical purpose, as well as for better accuracy of measurement [37, 39].

In the present study, both tooth root length and crown height were measured and the formula for EARR and EARR ratio were used. This method of measurement was used according to previous studies [39, 40] and chosen specifically to avoid any magnification error when analyzing $\mathrm{CBCT}$ scans. The formula was used on the basis that tooth crown height remains the same before and after the treatment. As a result, the difference of root length between the two time points represented the true root resorption amount.

From previous studies, it is generally considered that EARR of $1 \mathrm{~mm}$ or more during any 12-month period of active treatment is clinically significant $[41,42]$. In the present study, the mean EARR for the investigation subjects was $0.16 \pm 0.17 \mathrm{~mm}$ and was $0.07 \pm 0.05 \mathrm{~mm}$ for control subjects. Thus, the extent of root resorption for both groups were not clinically significant. Previous study has reported that the degree of EARR for fixed appliances is about $1.67 \pm 0.64 \mathrm{~mm}$ for maxillary central incisors [40]. Another recent study has shown an average of $1.12 \pm 1.34 \mathrm{~mm}$ root resorption for fixed appliance [20]. Thus, our data is in accordance with the previous study that the severity of EARR in patients using clear aligners was less than those using the fixed appliance. In addition, the severity of EARR in the investigational group was shown to be less than what has been reported

Table 3 Root resorption measurement: EARR ratio change from baseline in the two groups

\begin{tabular}{lllll}
\hline EARR Ratio (mean \pm SD, \%) & Aerodentis & Control & P-value & FDR \\
\hline Maxillary right canine & $1.40 \pm 1.46$ & $0.29 \pm 0.20$ & 0.0113 & 0.0714 \\
Maxillary right lateral incisor & $0.90 \pm 0.82$ & $0.55 \pm 0.19$ & 0.1258 & 0.1510 \\
Maxillary right central incisor & $0.92 \pm 0.83$ & $0.61 \pm 0.28$ & 0.194 & 0.1940 \\
Maxillary left central incisor & $0.80 \pm 1.20$ & $0.26 \pm 0.16$ & 0.0192 & 0.1432 \\
Maxillary left lateral incisor & $1.56 \pm 1.33$ & $0.62 \pm 0.37$ & 0.141 & 0.0714 \\
Maxillary left canine & $0.97 \pm 0.99$ & $0.53 \pm 0.38$ & 0.0866 & 0.1538 \\
Mandibular right canine & $1.57 \pm 1.67$ & $0.68 \pm 0.76$ & 0.0975 & 0.1432 \\
Mandibular right lateral incisor & $1.25 \pm 1.55$ & $0.51 \pm 0.31$ & 0.06 & 0.1432 \\
Mandibular right central incisor & $1.61 \pm 1.91$ & $0.54 \pm 0.37$ & 0.0221 & 0.1276 \\
Mandibular left central incisor & $1.20 \pm 0.94$ & $0.56+0.24$ & 0.0638 & 0.0714 \\
Mandibular left lateral incisor & $1.15 \pm 1.18$ & $0.45 \pm 0.26$ & 0.34 & 0.0714 \\
Mandibular left canine & $1.56 \pm 1.67$ & &
\end{tabular}


Table 4 Correlation between Little's Irregularity Index (LII) and root resorption

\begin{tabular}{llll}
\hline & Mean EARR & Mean Ratio & LII \\
\hline For all patients and mandibular site & & \\
Mean EARR & 1 & 0.95692 & 0.30198 \\
& & $<.0001$ & 0.1423 \\
Mean Ratio & 0.95692 & 1 & 0.36045 \\
& $<.0001$ & & 0.0767 \\
LII & 0.30198 & 0.36045 & 1 \\
\multirow{2}{*}{ For all patients and maxillary site } & 0.0767 & \\
Mean EARR & 1 & & 0.2836 \\
& & 0.95308 & 0.1897 \\
Mean Ratio & 0.95308 & $<.0001$ & 0.33696 \\
& $<.0001$ & 1 & 0.1159 \\
LII & 0.2836 & 0.33696 & 1 \\
& 0.1897 & 0.1159 & \\
\hline
\end{tabular}

with the fixed appliance, indicating that the fully controlled pulsating force may be more optimal than the force delivered by the fixed appliance.

Little's Index is the summation of the distances of the tooth contact points along the occlusal axis. It is used to assess anterior crowding and reflects rotation irregularities and displacement. In the present study, positive correlation was found between LII and the severity of root resorption. This is consistent with the previous study that duration of treatment and the horizontal displacement of the incisor apices were significantly associated with root resorption [43]. It is generally agreed that the larger the Little's index value, more anterior crowding is present. And it also takes a longer treatment time to move teeth. However, the positive correlation seen in this study was not statistically significant, possibly due to small sample size in the current study.

\section{Limitations}

Due to the obvious differences between the investigational and control devices, the users could not be blinded to their treatment arm. However, the investigators were blinded when doing the measurement for root resorption and the Little's Index.

The planned sample size (30 in the investigational group and 15 in the control group) was decided according to the power analysis, with $\alpha=0.05$ and $80 \%$ power. However, there were 5 investigational subjects and 2 control subjects who did not complete the trial. Although most participants $(80 \%)$ in the investigational group stated that they were very satisfied or satisfied with the device (data not shown), occasional technical issues, which were to be expected for a new technology, arose and led to the failure of some participants to finish the trial. We expect that new improvement be made to the device based on the data collected from this study.

\section{Conclusion}

This results from this study suggest that the investigational device delivering pulsating force is safe and can be used clinically. No clinically significant root resorption was observed for either the investigational or the control group, and investigational device did not cause root resorption greater than the control group.

Abbreviations

PDL: Periodontal ligament; CBCT: Cone beam computed tomography; CAD/ CAM: Computer-assisted design/computer assisted manufacturing;

EARR: External apical root resorption; CEJ: Cemento-enamel junctions; LII: Little's index; SD: Standard deviation; FDR: False discovery rate; TMJ: Temporomandibular joint

\section{Acknowledgements}

Not applicable.

\section{Authors' contributions}

All authors have made substantial contributions to conception and design of the study. CHK, EL and TC planned the study. CHK did the IRB, recruited participants, analyzed and interpreted the data, and prepared manuscript. EL and TC participated in participant recruitment and data collection. JW participated in preparing the IRB, data collection, and preparing manuscript. $\mathrm{PL}$ carried out the statistical analysis. All authors have revised the manuscript critically and have given final approval.

\section{Funding}

Not applicable.

\section{Availability of data and materials}

The data sets used and analyzed during the current study are available from the corresponding author upon reasonable request.

\section{Ethics approval and consent to participate}

Ethics approval and consent to participate by the Institutional Review Board for Human Use (IRB) of the University of Alabama at Birmingham. The ethics committee's reference number is F160418007. Written informed consent was obtained from a parent or guardian for participants under 16 years old.

Written informed consent was obtained from participants aged over 16 years old.

Consent for publication

Not applicable.

\section{Competing interests}

CHK is the principal investigator, and EL and TC are co-investigators on the clinical trial sponsored by Dror Orthodesign. The other authors have no conflicts of interest to disclose.

\section{Author details}

${ }^{1}$ Department of Orthodontics, School of Dentistry, Univeristy of Alabama at Birmingham, Room 305, School of Dentistry Building, 1919 7th Avenue South, Birmingham, AL 35294, USA. ${ }^{2}$ School of Nursing, University of

Alabama at Birmingham, Birmingham, AL, USA.

Received: 14 April 2020 Accepted: 18 August 2020

Published online: 27 August 2020

\section{References}

1. Shapiro E, Roeber F, Klempner L. Orthodontic movement using pulsating force-induced piezoelectricity. Am J Orthod. 1979;76(1):59-66.

2. Oates JC, Moore RN, Caputo AA. Pulsating forces in orthodontic treatment. Am J Orthod Dentofac Orthop. 1978;74(5):577-86. 
3. Hayashi H, Konoo T, Yamaguchi K. Intermittent 8-hour activation in orthodontic molar movement. Am J Orthod Dentofac Orthop. 2004;125(3): 302-9.

4. Igarashi K, Miyoshi K, Shinoda H, Saeki S, Mitani H. Diurnal variation in tooth movement in response to orthodontic force in rats. Am J Orthod Dentofac Orthop. 1998;114(1):8-14.

5. Blake M, Woodside D, Pharoah M. A radiographic comparison of apical root resorption after orthodontic treatment with the edgewise and speed appliances. Am J Orthod Dentofac Orthop. 1995;108(1):76-84.

6. Mavragani M, Bøe OE, Wisth PJ, Selvig KA. Changes in root length during orthodontic treatment: advantages for immature teeth. Eur J Orthod. 2002; 24(1):91-7.

7. Brezniak N, Wasserstein A. Root resorption after orthodontic treatment: part 2. Literature review. Am J Orthod Dentofac Orthop. 1993;103(2):138-46.

8. Linge $\mathrm{BO}$, Linge L. Apical root resorption in upper anterior teeth. Eur J Orthod. 1983;5(3):173-83

9. Levander $\mathrm{E}$, Malmgren $\mathrm{O}$. Evaluation of the risk of root resorption during orthodontic treatment: a study of upper incisors. Eur J Orthod. 1988;10(1): 30-8.

10. Weltman B, Vig KW, Fields HW, Shanker S, Kaizar EE. Root resorption associated with orthodontic tooth movement: a systematic review. Am J Orthod Dentofac Orthop. 2010;137(4):462-76.

11. Linge $L$, Linge $B O$. Patient characteristics and treatment variables associated with apical root resorption during orthodontic treatment. Am J Orthod Dentofac Orthop. 1991;99(1):35-43.

12. Wang J, Rousso C, Christensen BI, Li P, Kau CH, MacDougall M, Lamani E. Ethnic differences in the root to crown ratios of the permanent dentition. Orthod Craniofac Res. 2019;22(2):99-104.

13. Hartsfield J Jr, Everett ET, Al-Qawasmi R. Genetic factors in external apical root resorption and orthodontic treatment. Crit Rev Oral Biol Med. 2004; 15(2):115-22.

14. Sameshima GT, Sinclair PM. Predicting and preventing root resorption: part I. Diagnostic factors. Am J Orthod Dentofac Orthop. 2001;119(5):505-10.

15. Weiland F. Constant versus dissipating forces in orthodontics: the effect on initial tooth movement and root resorption. Eur J Orthod. 2003;25(4):33542.

16. Harris DA, Jones AS, Darendeliler MA. Physical properties of root cementum: part 8. Volumetric analysis of root resorption craters after application of controlled intrusive light and heavy orthodontic forces: a microcomputed tomography scan study. Am J Orthod Dentofac Orthop. 2006;130(5):639-47.

17. Chan E, Darendeliler MA. Physical properties of root cementum: part 7. Extent of root resorption under areas of compression and tension. Am J Orthod Dentofac Orthop. 2006;129(4):504-10.

18. Walton DK, Fields HW, Johnston WM, Rosenstiel SF, Firestone AR, Christensen JC. Orthodontic appliance preferences of children and adolescents. Am J Orthod Dentofac Orthop. 2010;138(6):698.e1-12.

19. Fujiyama K, Honjo T, Suzuki M, Matsuoka S, Deguchi T. Analysis of pain level in cases treated with Invisalign aligner: comparison with fixed edgewise appliance therapy. Prog Orthod. 2014;15(1):64.

20. Li Y, Deng S, Mei L, Li Z, Zhang X, Yang C, Li Y. Prevalence and severity of apical root resorption during orthodontic treatment with clear aligners and fixed appliances: a cone beam computed tomography study. Prog Orthod. 2020;21(1):1-8

21. Jiang R-p, McDonald J, Fu M-k. Root resorption before and after orthodontic treatment: a clinical study of contributory factors. Eur J Orthod. 2010;32(6):693-7.

22. Sherrard JF, Rossouw PE, Benson BW, Carrillo R, Buschang PH. Accuracy and reliability of tooth and root lengths measured on cone-beam computed tomographs. Am J Orthod Dentofac Orthop. 2010;137(4):S100-8

23. Palomo JM, Kau CH, Palomo LB, Hans MG. Three-dimensional cone beam computerized tomography in dentistry. Dent Today. 2006;25(11):130 132-135.

24. Lotan T, Ronen S. Orthodontic system with tooth movement and position measuring, monitoring, and control. In: Google Patents; 2018.

25. Kau CH. A radiographic analysis of tooth morphology following the use of a novel cyclical force device in orthodontics. Head Face Med. 2011;7:14.

26. Nimeri G, Kau CH, Corona R, Shelly J. The effect of photobiomodulation on root resorption during orthodontic treatment. Clin Cosmet Investig Dent. 2014;6:1-8.

27. Lind V. Short root anomaly. Eur J Oral Sci. 1972:80(2):85-93.

28. Hölttä P, Nyström M, Evälahti M, Alaluusua S. Root-crown ratios of permanent teeth in a healthy Finnish population assessed from panoramic radiographs. Eur J Orthod. 2004;26(5):491-7.
29. Aras I, Unal I, Huniler G, Aras A. Root resorption due to orthodontic treatment using self-ligating and conventional brackets. J Orofac Orthop/ Fortschritte der Kieferorthopädie. 2018;79(3):181-90.

30. Lund H, Gröndahl K, Hansen K, Gröndahl H-G. Apical root resorption during orthodontic treatment: a prospective study using cone beam $\mathrm{CT}$. Angle Orthod. 2012:82(3):480-7.

31. Gay G, Ravera S, Castroflorio T, Garino F, Rossini G, Parrini S, Cugliari G, Deregibus A. Root resorption during orthodontic treatment with Invisalign ${ }^{\oplus}$ : a radiometric study. Prog Orthod. 2017;18(1):12.

32. Katheria BC, Kau CH, Tate R, Chen JW, English J, Bouquot J. Effectiveness of impacted and supernumerary tooth diagnosis from traditional radiography versus cone beam computed tomography. Pediatr Dent. 2010;32(4):304-9.

33. Kheir NA, Kau CH. Measuring mandibular asymmetry in class I normal subjects using 3D novel coordinate system. Ann Maxillofac Surg. 2014;4(1): 34-8

34. Wong ME, Kau CH, Melville JC, Patel T, Spagnoli DB. Bone reconstruction planning using computer technology for surgical management of severe Maxillomandibular atrophy. Oral Maxillofac Surg Clin North Am. 2019;31(3): 457-72.

35. Kapila S, Nervina J. CBCT in orthodontics: assessment of treatment outcomes and indications for its use. Dentomaxillofac Radiol. 2015;44(1): 20140282

36. Wang J, Veiszenbacher E, Waite PD, Kau CH. Comprehensive treatment approach for bilateral idiopathic condylar resorption and anterior open bite with customized lingual braces and total joint prostheses. Am J Orthod Dentofac Orthop. 2019:156(1):125-36.

37. Al-Qawasmi RA, Hartsfield J Jr, Everett E, Flury L, Liu L, Foroud T, Macri J, Roberts W. Genetic predisposition to external apical root resorption in orthodontic patients: linkage of chromosome-18 marker. J Dent Res. 2003; 82(5):356-60.

38. Topkara A, Karaman Al, Kau CH. Apical root resorption caused by orthodontic forces: a brief review and a long-term observation. Eur J Dent 2012:6(4):445-53.

39. Mavragani $M$, Vergari A, Selliseth NJ, Bøe OE, Wisth PJ. A radiographic comparison of apical root resorption after orthodontic treatment with a standard edgewise and a straight-wire edgewise technique. Eur J Orthod. 2000;22(6):665-74

40. Mohandesan $\mathrm{H}$, Ravanmehr $\mathrm{H}$, Valaei N. A radiographic analysis of external apical root resorption of maxillary incisors during active orthodontic treatment. Eur J Orthod. 2007;29(2):134-9.

41. Proffit W. Treatment planning: the search for wisdom. In: Surgicalorthodontic treatment; 1991.

42. Copeland S, Green L. Root resorption in maxillary central incisors following active orthodontic treatment. Am J Orthod Dentofac Orthop. 1986;89(1):515.

43. Sameshima GT, Sinclair PM. Predicting and preventing root resorption: part II. Treatment factors. Am J Orthod Dentofac Orthop. 2001;119(5):511-5.

\section{Publisher's Note}

Springer Nature remains neutral with regard to jurisdictional claims in published maps and institutional affiliations.

Ready to submit your research? Choose BMC and benefit from

- fast, convenient online submission

- thorough peer review by experienced researchers in your field

- rapid publication on acceptance

- support for research data, including large and complex data types

- gold Open Access which fosters wider collaboration and increased citations

- maximum visibility for your research: over $100 \mathrm{M}$ website views per year

At $\mathrm{BMC}$, research is always in progress.

Learn more biomedcentral.com/submission 